\title{
Comparative outcome analysis of hydroxychloroquine/chloroquine, remdesivir and standard of care treatment against COVID-19 infection
}

\author{
Vikas Kumar, Sumit Kumar Mahato*
}

Department of Pharmacology, All India Institute of Medical Sciences, Rishikesh, Uttarakhand, India

Received: 12 November 2020

Accepted: 15 December 2020

\section{*Correspondence:}

Dr. Sumit Kumar Mahato,

Email: Sumitmahato2apr@gmail.com

Copyright: $(\odot$ the author(s), publisher and licensee Medip Academy. This is an open-access article distributed under the terms of the Creative Commons Attribution Non-Commercial License, which permits unrestricted non-commercial use, distribution, and reproduction in any medium, provided the original work is properly cited.

\begin{abstract}
This study aimed to compare the efficacy and safety of hydroxychloroquine/chloroquine (HCQ/CQ), remdesivir and standard of care treatment (SOC) in patients with $\mathrm{nCoV}-19$ based on the RCTs available in the literature. We conducted a cumulative review of all the RCTs published for the treatment of nCoV-19. Analysis for odds of patient recovery on $\mathrm{HCQ} / \mathrm{CQ}$, remdesivir and SOC treatment was accomplished and recovery was expressed as undetectable viral RNA levels. Total sample size in our analysis was 978 from six RCTs, in which nCoV-19 positive patients treated with HCQ/CQ, remdesivir and SOC were 166,560 and 252, respectively. SOC treatment showed increase in 2 -fold of patients' recovery as compared to the $\mathrm{HCQ} / \mathrm{CQ}$ group $(\mathrm{p}=0.0006)$. Further, patients reported $1.5-3$-fold increase in adverse events in remdesivir and HCQ/CQ group as compared to SOC group ( $\mathrm{p}=0.0016$ and $\mathrm{p}<0.0001)$. Our finding suggests remdesivir or HCQ/CQ ensures no benefit over SOC treatment, which may be attributed to the adverse events exhibited by remdesivir, or inefficacy of $\mathrm{HCQ} / \mathrm{CQ}$.
\end{abstract}

Keywords: nCoV-19, COVID-19, Hydroxychloroquine/chloroquine, Remdesivir, Standard of care

\section{INTRODUCTION}

The world health organization has declared novel coronavirus-19 (nCoV-19), outbreak as a global pandemic. ${ }^{1}$ As of June $202020, \mathrm{nCoV}-19$ has affected over 8.5 million people worldwide. ${ }^{2}$

nCoV-19 is a single-stranded RNA-enveloped virus, which binds with host cell surface angiotensin-converting enzyme 2 receptor (ACE2), through its structural spike protein. Entry of virus is facilitated by receptor-mediated endocytosis and the virus releases its RNA into the host cell. Further, the viral RNA is translated into polyproteins for viral replication, and thereby leading to infection of the host cell. ${ }^{3}$

The virus is isolated from naso and oropharyngeal specimens from putative COVID-19 patients and detected by reverse transcription polymerase chain reaction (RTPCR). It is unclear how long patients remain contagious, as a period of infectivity of patients' do not corroborate with viral RNA shedding after resolution of symptoms. The median duration of viral RNA shedding was found to be a minimum of 24 days to a maximum of 42 days. ${ }^{4}$

The spectrum of clinical manifestation is unclear. Symptoms range from mild to moderate and moderate to severe, even leading to death. Common manifestations include sore throat, cough, fever, running nose, myalgia, shortness of breath, pneumonia and multi-organ failure. Severely ill patients suffer from acute respiratory distress syndrome leading to respiratory failure due to alveolar damage. It is commonly observed that elderly and middleaged patients with comorbidities like coronary heart disease, diabetes, hypertension and renal disease are at more risk to death. 
The current recommendations have advocated the use of $\mathrm{HCQ} / \mathrm{CQ}$ and remdesivir as potential pharmacological agents against nCoV-19. HCQ/CQ is approved for the prevention and treatment of malaria, rheumatoid arthritis, systemic lupus erythematosus and other chronic inflammatory diseases. Antiviral activities of HCQ/CQ seem to prevent viral entry into cells by inhibiting glycosylation of host receptors, proteolytic processing, and endosomal acidification. Immunomodulatory effects occur via decrease in cytokine production, inhibition of autophagy and lysosomal activity in host cells. ${ }^{3}$ Currently, HCQ/CQ is administered at variable doses $(200-800 \mathrm{mg})$, however, optimal dose to ensure safety and efficacy is debatable. RCTs need to be conducted to explore the optimal dose for nCoV-19 treatment, as we have vast experience in patients with SLE and malaria. The safety issues with HCQ/CQ reported are QTc prolongation, neuropsychiatric effects, hypoglycaemia and retinopathy. ${ }^{3}$ Therefore, it is recommended to evaluate baseline electrocardiogram before initiating the therapy. Remdesivir is a prodrug that undergoes metabolism to become an active c-adenosine nucleoside triphosphate analogue. It acts by inhibiting RNA dependent RNA polymerase enzyme. Remdesivir has shown antiviral activity against RNA viruses, Coronaviridae, Flaviviridae and Ebola virus. The current recommended loading dose is $200 \mathrm{mg}$, followed by $100 \mathrm{mg}$ daily infusion. Multipledose administrations can lead to reversible elevation of aspartate aminotransferase and alanine transaminase. It is not recommended in pregnant and lactating mothers, children below 12 years of age and in patients with an estimated glomerular filtration rate less than $30 \mathrm{~mL} / \mathrm{min}^{3}$

Currently, there is neither an established standard treatment guideline nor approval of specific drugs from the United States food and drug administration (U.S. FDA) for the management of nCoV-19 disease. Repurposed drugs with antiviral activity are currently used for the management of nCoV-19. There is an urgent need for specific medication against the current pandemic due to nCoV-19. Further, the data obtained from several observational studies on COVID-19 have been inconclusive. Moreover, limited data is available from randomized clinical trials (RCTs), though multiple RCTs are being conducted for exploring the effective therapeutic strategies against nCoV-19 infection. The safety and efficacy of currently used medications are a matter of debate. Our analysis aimed to compare the superior efficacy of different treatments like HCQ/CQ vs remdesivir vs SOC against $\mathrm{nCoV}-19$ infection, based on the collective data obtained from RCTs. ${ }^{6-11}$

\section{METHODS}

We reviewed the existing literature on June 20, 2020 for all the RCTs demonstrating the treatment strategies against nCoV-19. The search terms used were (COVID-19 or 2019-nCoV or SARS-CoV-2) and remdesivir and (clinical trial or randomized controlled trial) and (COVID-19) and (randomized controlled trial) in PubMed. We only selected
RCTs to ensure the highest level of evidence for the nCoV19 treatment. ${ }^{4}$ SOC treatment included, as necessary oxygen supplementation, ventilation support, antibiotic, vasopressor support, renal replacement therapy and extracorporeal membrane oxygenation. ${ }^{7}$ We collected the data from RCTs which comprised of demographic, associated comorbidities, mean duration of treatment, mortality, patient recovered and adverse events. Analysis was performed for odds of patients' recovery on HCQ/CQ vs remdesivir vs SOC treatment and was expressed as undetectable viral RNA levels.

\section{Statistical analysis}

Cumulative data from selected RCTs $(n=6)$ were categorized into $\mathrm{HCQ} / \mathrm{CQ}$, remdesivir and SOC groups. Baseline demographic characteristics were expressed in mean, ratio and percentages. Odds ratio of recovery in $\mathrm{HCQ} / \mathrm{CQ}$, remdesivir and SOC groups was evaluated by $\mathrm{Z}$ test with $95 \%$ confidence interval (CI) and was represented as forest plot. A Kaplan-Meier plot was used to estimate the overall recovery curves. Recovery curves of the three treatment groups were compared using the log-rank test.

\section{RESULTS}

The total sample size in our analysis was 978 from six RCTs, in which 166 COVID-19 positive patients received $\mathrm{HCQ} / \mathrm{CQ}, 560$ subjects were treated with remdesivir and 252 patients received SOC treatment. Mean age of the study subjects was 47,64 and 55 years, respectively. The number of male patients were 110 in HCQ/CQ, 342 in remdesivir and 150 in SOC group. The severity of the patients was categorized as a ratio of mild to moderate and severe, which was 78:88, 0:560 and 75:178, respectively. In each group, comorbid conditions i.e. diabetes and hypertension were recorded. $16 \%$ of patients were diabetic in HCQ/CQ group, while 23 and $15 \%$ of subjects were found to be diabetic in remdesivir and SOC group, respectively. Hypertension was observed in $19 \%$ of patients on HCQ/CQ as compared with up to 48 and $13 \%$ of subjects in remdesivir and SOC-treated group. Mean duration of treatment was 11,8 and 10 days in each group. At the end of the study, the mortality rate was observed in HCQ/CQ group was 13 and $11 \%$ in remdesivir group and $14 \%$ in SOC group. The patients' survival rate at the end of the study period was 42,89 and $85 \%$ in all the respective groups (Table 1). Probability of negative conversion, which was expressed as undetectable viral RNA count was higher as $62 \%$ in SOC group as compared to $45 \%$ in $\mathrm{HCQ} / \mathrm{CQ}$ group and $58 \%$ in remdesivir group $(\mathrm{OR}=2.0052, \mathrm{p}=0.0006$ and $\mathrm{OR}=0.8368, \mathrm{p}=0.2525)$ (Table 1 and 2). In HCQ/CQ group, 56\% patients experienced adverse events, $69 \%$ in remdesivir group as compared to $42 \%$ in SOC group $(\mathrm{OR}=1.7707, \mathrm{p}=0.0016$ and $\mathrm{OR}=3.1071, \mathrm{p}<0.0001$ ) (Table 1 and 3 ). The overall patients' recovery was $45 \%$ in HCQ/CQ group, while 58 and $62 \%$ observed in remdesivir and SOC group, respectively ( $\mathrm{p}=0.0036, \mathrm{p}=0.0006)$ (Figure 1 and 2). 
Table 1: Comparative analysis between hydroxychloroquine/chloroquine, remdesivir and standard of care.

\begin{tabular}{|llll|}
\hline Characteristics & HCQ/CQ & Remdesivir, & SOC $^{7-9}$ \\
\hline Sample size (n) & 166 & 560 & 252 \\
\hline Mean age (years) & 47 & 64 & 55 \\
\hline Gender (M:F) & $110: 56$ & $342: 218$ & $150: 102$ \\
\hline Severity (mild to moderate:severe) & $78: 88$ & $0: 560$ & $75: 178$ \\
\hline Co-morbidities & & & $38(15)$ \\
\hline Diabetes (\%) & $27(16)$ & $130(23)$ & $33(13)$ \\
\hline Hypertension (\%) & $32(19)$ & $270(48)$ & 10 \\
\hline Mean duration of treatment (days) & 11 & 8 & - \\
\hline Doses (mg)/route & $450,600,800 /$ oral & $100 / \mathrm{IV}$ & $35(14)$ \\
\hline Mortality (\%) & $22(13)$ & $59(11)$ & $213(85)$ \\
\hline Patient's survived (\%) & $69(42)$ & $501(89)$ & $157(62)$ \\
\hline No. of patients recovered (\%) & $75(45)$ & $325(58)$ & $106(42)$ \\
\hline Adverse events (\%) & $93(56)$ & $388(69)$ & \\
\hline
\end{tabular}

HCQ/CQ-hydroxychloroquine/chloroquine, SOC-standard of care

Table 2: Odds ratio for patients' recovery, depicting the comparison in treatment efficacy among $\mathrm{HCQ} / \mathrm{CQ}$, remdesivir and SOC groups.

\begin{tabular}{|lllll|}
\hline Groups & Odds ratio & $95 \%$ CI & Z-test & P value \\
\hline SOC vs remdesivir & 0.8368 & $0.6168-1.1354$ & 1.144 & 0.2525 \\
\hline SOC vs HCQ/CQ & 2.0052 & $1.3469-2.9852$ & 3.427 & $0.0006^{*}$ \\
\hline Remdesivir vs HCQ/CQ & 0.5959 & $0.4205-0.8446$ & 2.909 & $0.0036^{*}$ \\
\hline SOC vs other treatments & 0.7424 & $0.5535-0.9960$ & 1.987 & $0.0469^{*}$ \\
\hline
\end{tabular}

HCQ/CQ-hydroxychloroquine/chloroquine, SOC-standard of care, other treatments-cumulative data from remdesivir and HCQ/CQ grp.

Table 3: Odds ratio for patients' adverse safety events, illustrate the comparisons among HCQ/CQ, remdesivir and SOC groups

\begin{tabular}{|lllll|}
\hline Groups & Odds ratio & $95 \%$ C. I & Z test & P value \\
\hline Remdesivir vs SOC & 3.1071 & $2.2837-4.2273$ & 7.217 & $<0.0001^{*}$ \\
\hline HCQ/CQ vs SOC & 1.7547 & $1.1814-2.6062$ & 2.786 & $0.0053^{*}$ \\
\hline Remdesivir vs HCQ/CQ & 1.7707 & $1.2413-2.5258$ & 3.153 & $0.0016^{*}$ \\
\hline SOC vs other treatments & 0.3698 & $0.2757-0.4960$ & 6.640 & $<0.0001^{*}$ \\
\hline
\end{tabular}

*P value $<0.05$ was considered significant.

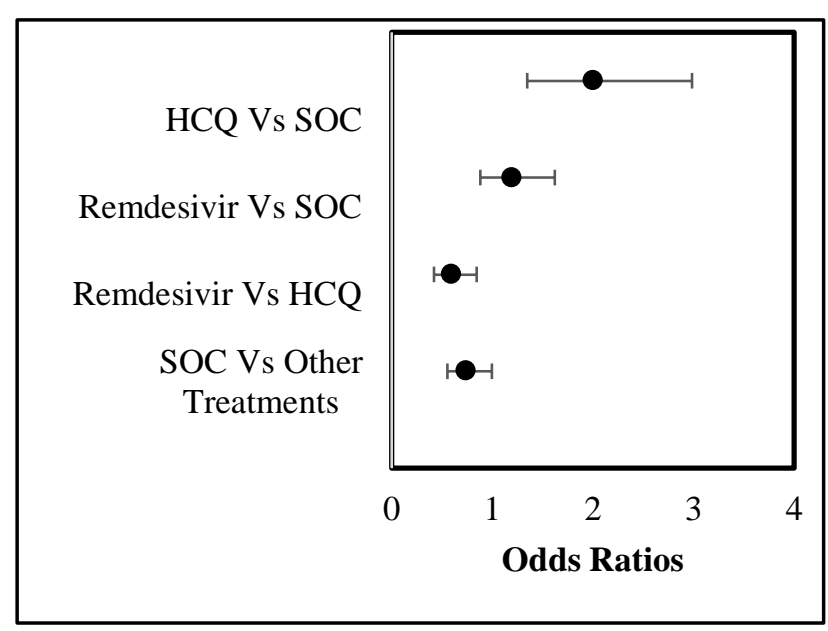

Figure 1: Forest plot of odds ratio for patients' recovery, depicting comparison in treatment efficacy among $\mathrm{HCQ} / \mathrm{CQ}$, remdesivir and SOC groups.

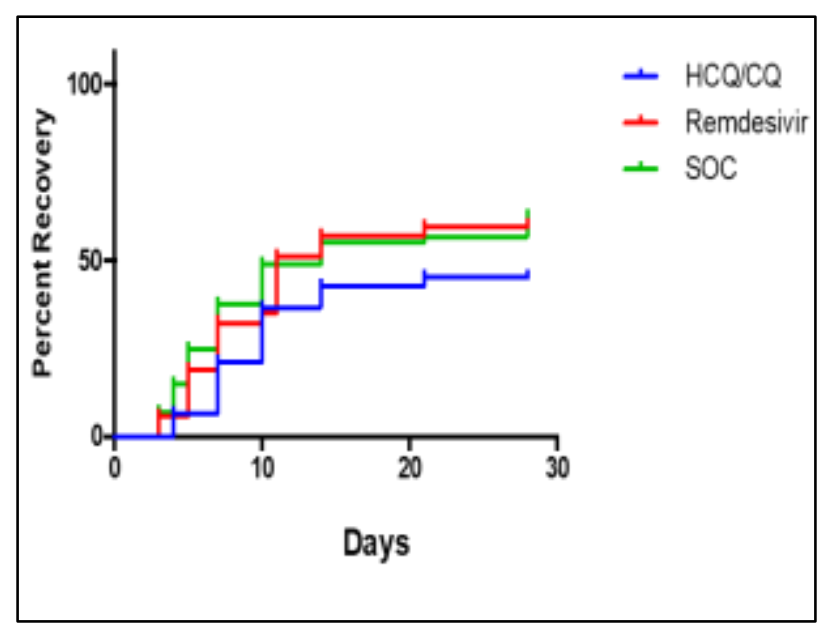

Figure 2: Comparison of cumulative patients' recovery rate between $H C Q / C Q$, remdesivir and $S O C$ groups. $\mathrm{P}$ values (log rank test) was $\mathbf{0 . 0 0 0 6}$. 


\section{DISCUSSION}

Based on the existing literature on RCTs, our study compared the efficacy and safety of $\mathrm{HCQ} / \mathrm{CQ}$, remdesivir and SOC treatment. The virologic clearance was considered as a gold standard indicator for patients' recovery, which was used as an efficacy parameter in all the previous RCT studies. Adverse events were also monitored during the follow-up period as a safety outcome measure.

Some studies have shown the beneficial effect of HCQ/CQ and remdesivir for the treatment against $\mathrm{nCoV}-19$ patients. Gao et al reported the efficacy and safety of chloroquine against COVID-19 associated pneumonia from multi center clinical trials. They demonstrated improved outcomes in terms of radiologic findings, enhanced viral clearance, and reduced disease progression. ${ }^{12}$ However, the use of chloroquine is associated with more chances of adverse drug reactions. Another study by Gautret et al, was an open-label nonrandomized clinical study, enrolled 36 patients with a follow-up of 6 days (20 in the HCQ group with a dose of $200 \mathrm{mg}$ orally every 8 hourly and 16 in the control group receiving standard supportive care). At the end of the study, improved virologic clearance was seen in HCQ group as compared to control group $(\mathrm{p}=0.001){ }^{13}$ Limitations of the study were a small sample size, nonrandom allocation of participants and small duration of follow-up. Jacobs et al reported the first clinical use of remdesivir for the treatment of Ebola. ${ }^{14}$ Holshue and Kujawski et al reported successful use of remdesivir for COVID-19. ${ }^{15,16}$ However, efficacy of remdesevir cannot be ascertained on the basis of case reports.

Our results demonstrated that neither $\mathrm{HCQ} / \mathrm{CQ}$ nor remdesivir showed superiority in efficacy and safety in comparison to standard of care treatment. As there are limited evidence from available RCTs, our analysis showed that the odds of recovery in $\mathrm{nCoV}-19$ positive patients were observed to be highly significant with SOC in comparison to $\mathrm{HCQ} / \mathrm{CQ}$-treated group. However, the efficacy of remdesivir was comparable to SOC, though, safety issues with remdesivir and HCQ/CQ are still a matter of concern. HCQ/CQ used alone or in combination poses chances of additive cardiotoxicity and evidence for appropriate effective dose is lacking that does not support adoption of any regimen without additional RCTs. ${ }^{3}$ The clinical trial demonstrated the safety and pharmacokinetics parameters in single and multiple-dose of remdesivir. Intravenous infusions between $3 \mathrm{mg}$ and $225 \mathrm{mg}$ were well-tolerated without any evidence of liver or kidney toxicity. However, previous observational studies demonstrated limitations of its use in patients with deranged liver and renal functions. ${ }^{3}$ Therefore, we advocate the use of large scale of RCTs to establish a better alternative treatment strategy with profound efficacy and safety to curtail the prevailing nCoV-19 pandemic. To the best of our knowledge, this is the first cumulative analysis of the published RCTs to elucidate the safety and efficacy of currently used medication for nCoV-19.

\section{CONCLUSION}

We conclude based on our findings that remdesivir or HCQ/CQ exerts no beneficial effect over SOC treatment, which may be due to the inefficacy of curative potential of $\mathrm{HCQ} / \mathrm{CQ}$, and the occurrence of adverse drug events by remdesivir treatment.

\section{Funding: No funding sources Conflict of interest: None declared Ethical approval: Not required}

\section{REFERENCES}

1. Available at: https://www.who.int/newsroom/detail/27-04-2020who-timeline---covid-19. Accessed on 10 August 2020.

2. Available at: http://www.who.int/docs/default source/coronaviruse/situation-reports/20200620covid-19-sitrep-152.pdf?sfvrsn=83aff8ee_2. Accessed on 10 August 2020.

3. Sanders JM, Monogue ML, Jodlowski TZ, Cutrell JB. Pharmacologic Treatments for Coronavirus Disease 2019 (COVID-19): A Review. JAMA. 2020;323(18):1824-36.

4. Zheng S, Fan J, Yu F. Viral load dynamics and disease severity in patients infected with SARS-CoV-2 in Zhejiang province, China, retrospective cohort study. BMJ. 2020;369:m1443.

5. Hamid S, Mir MY, Rohela GK. Novel coronavirus disease (COVID-19): a pandemic (epidemiology, pathogenesis and potential therapeutics). New Microbes New Infect. 2020;35:100679.

6. Borba MGS, Val FFA, Sampaio VS. Effect of High vs Low Doses of Chloroquine Diphosphate as Adjunctive Therapy for Patients Hospitalized with Severe Acute Respiratory Syndrome Coronavirus 2 (SARS-CoV-2) Infection: A Randomized Clinical Trial. JAMA Netw Open. 2020;3:e208857.

7. Cao B, Wang Y, Wen D. A Trial of LopinavirRitonavir in Adults Hospitalized with Severe Covid19. N Engl J Med. 2020;382:1787-99.

8. Tang W, Cao Z, Han M, Wang Z, Chen J, Sun W et al. Hydroxychloroquine in patients with mainly mild to moderate coronavirus disease 2019: open label, randomised controlled trial. BMJ. 2020;369:m1849.

9. Wang Y, Zhang D, Du G, Du R, Zhao J, Jin Y et al. Remdesivir in adults with severe COVID-19: a randomised, double-blind, placebo-controlled, multicentre trial. Lancet. 2020;395:1569-78.

10. Goldman JD, Lye DCB, Hui DS, Marks KM, Bruno $\mathrm{R}$, Montejano R. Remdesivir for 5 or 10 Days in Patients with Severe Covid-19. N Engl J Med. 2020;383(19):1827-37.

11. Huang M, Tang T, Pang P, Li M, Ma R, Lu J et al. Treating COVID-19 with Chloroquine. J Mol Cell Biol. 2020;12:322-5.

12. Gao J, Tian $\mathrm{Z}$ and Yang $\mathrm{X}$. Breakthrough: Chloroquine phosphate has shown apparent efficacy 
in treatment of COVID-19 associated pneumonia in clinical studies. Biosci Trends. 2020;14:72-3.

13. Gautret P, Lagier JC, Parola P, Hoang VT, Meddeb L, Mailhe $\mathrm{M}$ et al. Hydroxychloroquine and azithromycin as a treatment of COVID-19: results of an open-label non-randomized clinical trial. Int $\mathrm{J}$ Antimicrob Agents. 2020:56(1):105949.

14. Jacobs M, Rodger A, Bell DJ, Bhagani S, Cropley I, Filipe $\mathrm{F}$ et al. Late Ebola virus relapse causing meningoencephalitis: a case report. Lancet. 2016;388:498-503.

15. Holshue ML, DeBolt C, Lindquist S, Lofy KH, Wiesman J, Bruce H et al. First Case of 2019 Novel
Coronavirus in the United States. N Engl J Med. 2020;382:929-36.

16. Team C-I. Clinical and virologic characteristics of the first 12 patients with coronavirus disease 2019 (COVID-19) in the United States. Nat Med. 2020;26(6):861-8.

Cite this article as: Kumar V, Mahato SK. Comparative outcome analysis of hydroxychloroquine/chloroquine, remdesivir and standard of care treatment against COVID-19 infection. Int J Basic Clin Pharmacol 2021;10:122-6. 